UV imprinting for thin film solar cell application

This article has been downloaded from IOPscience. Please scroll down to see the full text article.

2012 J. Opt. 14024009

(http://iopscience.iop.org/2040-8986/14/2/024009)

View the table of contents for this issue, or go to the journal homepage for more

Download details:

IP Address: 128.178.203.251

The article was downloaded on 24/05/2012 at 10:34

Please note that terms and conditions apply. 


\title{
UV imprinting for thin film solar cell application
}

\author{
J Escarré, C Battaglia, K Söderström, C Pahud, R Biron, \\ O Cubero, F-J Haug and C Ballif
}

Ecole Polytechnique Fédérale de Lausanne (EPFL), Institute of Microengineering (IMT), Photovoltaics and Thin Film Electronics Laboratory, Rue A-L Breguet 2, 2000 Neuchâtel, Switzerland

E-mail: jordi.escarre@epfl.ch

Received 30 June 2011, accepted for publication 23 September 2011

Published 12 January 2012

Online at stacks.iop.org/JOpt/14/024009

\begin{abstract}
UV imprinting is an interesting, low cost technique to produce large area thin film solar cells incorporating nanometric textures. Here, we review and present new results confirming that replicas of the most common textures used in photovoltaics can be obtained by UV imprinting with an excellent fidelity. The use of these replicas as substrates for amorphous and micromorph thin film silicon solar cells is also shown, together with a comparison with devices obtained on the original textures.
\end{abstract}

Keywords: solar cells, light trapping, UV imprinting, photovoltaics, thin film, plastic substrates

(Some figures in this article are in colour only in the electronic version)

\section{Introduction}

In recent years, great effort has been devoted to improving and developing novel optical confinement techniques for thin film silicon solar cells. An efficient light trapping makes possible thinner devices without diminishing their absorption. For amorphous silicon (a-Si:H), this leads to more stable solar cells while, for microcrystalline material $(\mu \mathrm{c}-\mathrm{Si}: \mathrm{H})$, it contributes to lower the production costs and to improve carrier collection.

In thin film silicon solar cells, the active semiconductor is placed between two transparent conductor oxide (TCO) layers. Light trapping is achieved by scattering the incoming light inside the device. In superstrate configuration $(\mathrm{p}-\mathrm{i}-\mathrm{n})$, nanometric random roughnesses, either developed during the growth or by a subsequent chemical attack of the TCO layers, are responsible for scattering the light. Common approaches are pyramidal type textures appearing after growing $\mathrm{ZnO}$ by low pressure chemical vapor deposition (LPCVD) under certain deposition conditions [1], or crater type textures obtained after etching of sputtered $\mathrm{ZnO}$ with hydrochloric acid [2]. In substrate configuration ( $n-i-p)$, where the substrate transparency is not mandatory, the texture developed by sputtering silver on substrates at high temperatures $\left(\sim 400^{\circ} \mathrm{C}\right)$ [3] or the use of novel nanocone textures [4] have proven to be very efficient to optically confine the light.
Although these textures have been shown to be very efficient, there is still room for improvement.

The search for the optimum texture combines simulation work, fabrication and final tests and optimization in devices. For nanometric periodic textures, it is possible to rigorously simulate the device performance, but their fabrication involves the use of expensive techniques like focused ion beam (FIB), electron beam lithography (EBL) or reactive ion etching (RIE) [5]. The engraving of a square centimeter area can require several days of work and is usually done on silicon or quartz wafers. However, through replication techniques this work has to be accomplished only once in order to obtain a master texture; subsequent recombination of small master textures is used to create bigger ones and transferring them onto cheaper substrates. The replication processes allow fabricating from a single master the number of samples necessary to carry out the challenging task of device optimization on nanostructured substrates, whenever their feature size is compatible with the thin film silicon growth process. Moreover, the replication processes make it possible to look for novel light trapping textures in nature. The nanostructures of a butterfly wing, or even the ones of a lotus leaf, can be copied [6]. The possibility of testing such a variety of structures and copying the one that performs the best, as 
nature automatically does, will be the way to further optimize the light trapping in solar cell devices.

Ultraviolet nanoimprint lithography (UV-NIL) and hot embossing lithography (HEL) techniques are commonly used to transfer a master texture onto another substrate in a controlled way. In hot embossing, the stamping is performed either to a polymer substrate heated above its glass transition temperature [7] or on temperature-curable resins [8, 9]. In UV-NIL, a UV-curable lacquer is required. Generally, UVNIL achieves higher resolution, requires less pressure and imposes no temperature limitation on the substrate. For thin film silicon cells prepared in the $n-i-p$ configuration, the UV imprinting can be used on flexible substrates allowing roll to roll deposition to further reduce manufacturing costs [10]. In superstrate configuration, the UV resins with high transmittance in the visible and near-infrared part of the spectrum make it possible to obtain any kind of texture on glass, even those where the master surface is opaque.

In the last few years, our group demonstrated that UV nanoimprinting can be successfully used in thin film silicon solar cell applications [11-15]. In this work we review and present new results, further confirming that high fidelity replicas can be obtained by UV nanoimprinting of the most commonly used textures in photovoltaics. In addition to a rigorous morphological characterization, we present also amorphous silicon solar cells deposited on master and replicas in both superstrate and substrate configuration, and we demonstrate comparable efficiency. We also show by an example that the same approach can be extended to micromorph technology by demonstrating devices with $12 \%$ initial efficiency on UV imprinted substrates in superstrate configuration. However, note that the interest in these replicated nanostructures is not unique to thin film silicon technology but also to other fields such as organic solar cells [16].

\section{Experimental details}

Glass (0.5 mm thick, Schott AF45) and polyethylenenaphthalate (PEN) (0.125 mm thick, Goodfellow Ltd) with a size of $4 \times 4 \mathrm{~cm}^{2}$ were used as the substrate in the replication experiments. Four types of disordered random structures typically used in photovoltaics were used as a master: textured $\mathrm{ZnO}$ :B grown by LPCVD, silver sputtered at high temperature, sputtered $\mathrm{ZnO}$ etched using hydrochloric acid $(\mathrm{HCl})$ to produce a frosted appearance, and a (100) crystalline silicon (c-Si) wafer textured using a low concentration potassium hydroxide solution $(\mathrm{KOH})$.

For the UV-NIL stamping experiments, negative molds were fabricated in order to obtain UV replicas with exactly the same texture as the original ones. These molds were obtained by UV embossing of the master texture into a commercially available UV sensitive sol-gel lacquer (Ormocer from Micro Resist Technology $\mathrm{GmbH}$ ) spin coated onto a flexible PEN sheet. After demolding, the stamps were coated with a thin layer of chromium $(\sim 40 \mathrm{~nm})$, an antiadhesion monolayer of fluoroalkylsilane, and used to transfer the positive structure on glass or PEN. Figure 1 summarizes the different steps of

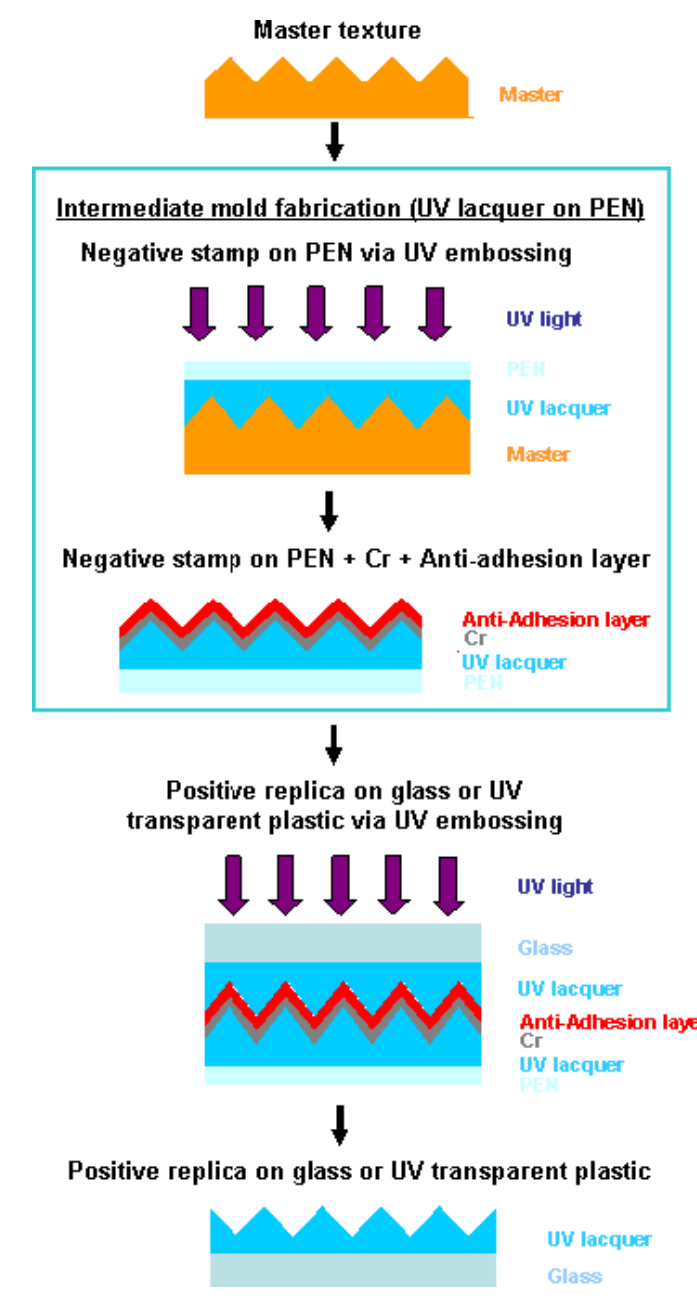

Figure 1. Replication process steps followed for the transfer of a master texture on glass or PEN by UV embossing [12].

this high fidelity replication process which has been presented previously [15].

UV-NIL stamping was carried out in a 'homemade' system. The system consists of two chambers separated by a flexible silicone membrane. During the process, both chambers are simultaneously evacuated, isolated and the upper chamber returned to atmospheric pressure by gently opening a valve. The difference in pressure $(\sim 1$ bar) between chambers causes the flexible membrane to expand against the lower one. The mold-substrate assembly is placed on the UV transparent bottom of the lower chamber. Contacting under vacuum conditions prevents the formation of bubbles in the UV-curable lacquer. The photocurable lacquer is then exposed to a moderate intensity $\left(1.4 \mathrm{~mW} \mathrm{~cm}^{-2}\right)$ of $\mathrm{UV} \operatorname{light}(\sim 365 \mathrm{~nm})$ coming through the substrate. Thus, in our system the exposure time necessary to cure the lacquer depends on the substrate used. Glass substrates require lower exposure $(\sim 1 \mathrm{~min})$ than PEN ( $\sim 20 \mathrm{~min}$ ) because of their lower UV absorption.

Replication fidelity of the sub- $\mu \mathrm{m}$ textures was studied morphologically by means of atomic force microscopy (AFM). As in previous publications $[12,15]$, the root mean square roughness $\left(\sigma_{\mathrm{RMS}}\right)$, the correlation length $(L)$ and the mean angle $(\langle\alpha\rangle)$ were extracted from the AFM images to compare 
master and replicas in a quantitative way. The micrometric pyramidal texture on the $\mathrm{c}-\mathrm{Si}$ wafer and its replica were studied by scanning electron microscopy (SEM) since their huge roughness did not allow AFM measurements. The 3D reconstruction of these pyramidal surfaces was achieved by means of a stereoscopic technique based on the one described by Kuchler [17]. The same sample area was scanned twice but with different tilting. The tilt angles used were $0^{\circ}$ and $15^{\circ}$. The height of the pyramids $(z)$ was determined from the lateral shift $\left(y^{\prime}-y\right)$ in the position of their peaks caused by a different viewing angle. The relation between the coordinates of the peaks in a non-tilted $(y, z)$ and $\beta^{\circ}$ tilted $\left(y^{\prime}, z^{\prime}\right)$ reference system is given by a simple rotation formula:

$$
y^{\prime}=y \cos \beta-z \sin \beta,
$$

yielding the following expression for the height of the pyramids:

$$
z=\frac{y \cos \beta-y^{\prime}}{\sin \beta} .
$$

Once the coordinates of the peaks were determined, the surface was completed by adding the pyramid facets. From each peak four semi-infinite planes were extended downward with a slope of $54.7^{\circ}$ which is the angle that the (111) silicon plane walls form with respect to the horizontal (100) plane [18]. The surface reconstruction was finished by taking for each surface point the maximum vertical value of the whole set of facets. Correlation length and $\sigma_{\text {RMS }}$ were extracted from the reconstructed texture to have a quantitative comparison between the micrometric pyramidal texture of master and replica.

Replication fidelity was further studied using LPCVD $\mathrm{ZnO}$ replicas as substrates for a-Si:H solar cells in superstrate and substrate configuration. Figure 2 outlines the different layers used in the front and back part of the devices grown on replicas for both types of configuration. In superstrate configuration, an indium-tin oxide (ITO) layer was used as a front electrode ( $\sim 110 \mathrm{~nm}$ thick). More details on the optical and electrical properties of this layer can be found in [19]. Moreover, a thin layer of aluminum doped $\mathrm{ZnO}(\sim 20 \mathrm{~nm}$ thick $)$ was sputtered on top to protect ITO from chemical reduction caused by the hydrogen-rich plasma environment during the silicon deposition, because $\mathrm{ZnO}$ films are not reduced during exposure to atomic hydrogen [20]. In substrate configuration, a back reflector consisting of silver and aluminum doped $\mathrm{ZnO}$ was used. The layers were sputtered at room temperature with a nominal thickness of 120 and $60 \mathrm{~nm}$, respectively.

The a-Si:H solar cells were deposited at a substrate temperature of $190^{\circ} \mathrm{C}$ by plasma enhanced chemical vapor deposition (PECVD). Sputtered ITO with a thickness of $65 \mathrm{~nm}$ was used as a front contact for the $\mathrm{n}-\mathrm{i}-\mathrm{p}$ cells. A non-metallic back reflector consisting of $5 \mu \mathrm{m}$ thick LPCVD ZnO covered by a white paint was used for the $\mathrm{p}-\mathrm{i}-\mathrm{n}$ devices.

The solar cells were characterized by measuring $I-V$ and external quantum efficiency (EQE). $I-V$ measurements were carried out using a dual lamp solar simulator (Wacom WXS-140S-10) in standard test conditions (STC, $25^{\circ} \mathrm{C}$, Air Mass 1.5 global (AM $1.5 \mathrm{~g}$ ) spectrum, and (a)

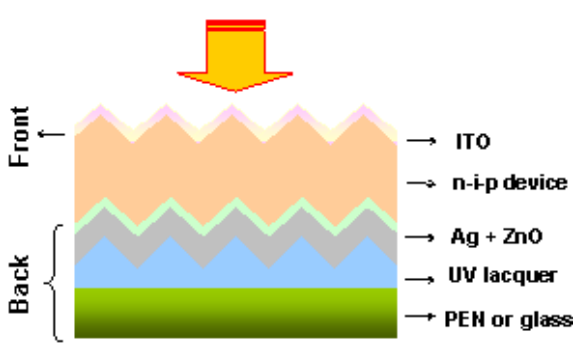

(b)

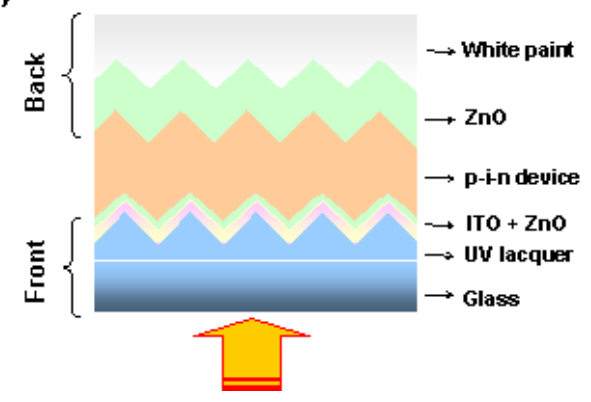

Figure 2. Layer scheme of the devices grown on imprinted substrates either in (a) $n-i-p$ or (b) $\mathrm{p}-\mathrm{i}-\mathrm{n}$ configuration.

$\left.1000 \mathrm{~W} \mathrm{~m}^{-2}\right)$. The open circuit voltage $\left(V_{\mathrm{oc}}\right)$ and the fill factor (FF) were determined from the $I-V$ measurement; the short circuit current density $\left(J_{\mathrm{SC}}\right)$ of the devices was calculated by integrating over the EQE curve after weighting with the AM $1.5 \mathrm{~g}$ spectrum.

\section{Results and discussion}

\subsection{UV-NIL stamping}

The superficial structure of the masters and their corresponding replicas obtained on glass are presented in figure 3 . The images comparing each master and replica were taken from randomly selected areas but with the same size. Visual inspection reveals no significant difference between master and replica for the four different textures.

In order to quantitatively analyze the fidelity of the replication, the same procedure as described in previous publications was used to compare AFM images [12, 15]. A summary of the $\sigma_{\mathrm{RMS}}$, correlation length and mean angle values calculated for the LPCVD $\mathrm{ZnO}$, the sputtered silver and the sputtered etched $\mathrm{ZnO}$ textures is shown in table 1. No significant deviation was observed in these numerical parameters between originals and replicas. This information is complemented by comparing the height and angle histograms (figure 4). Both histograms are practically identical for each sort of master and replica, the only apparent differences are observed in the angle histogram of the sputtered etched $\mathrm{ZnO}$, where the replica shows a slight shift toward lower angles. A possible explanation is the big size of the crater features which form their surface. The lateral size of these features is estimated to be $0.7-0.8 \mu \mathrm{m}$, almost double that of the other two textures, according to the calculated correlations in the diameters (see table 1). Moreover, there is an important variation in their size, some of them reaching up to $2 \mu \mathrm{m}$. 

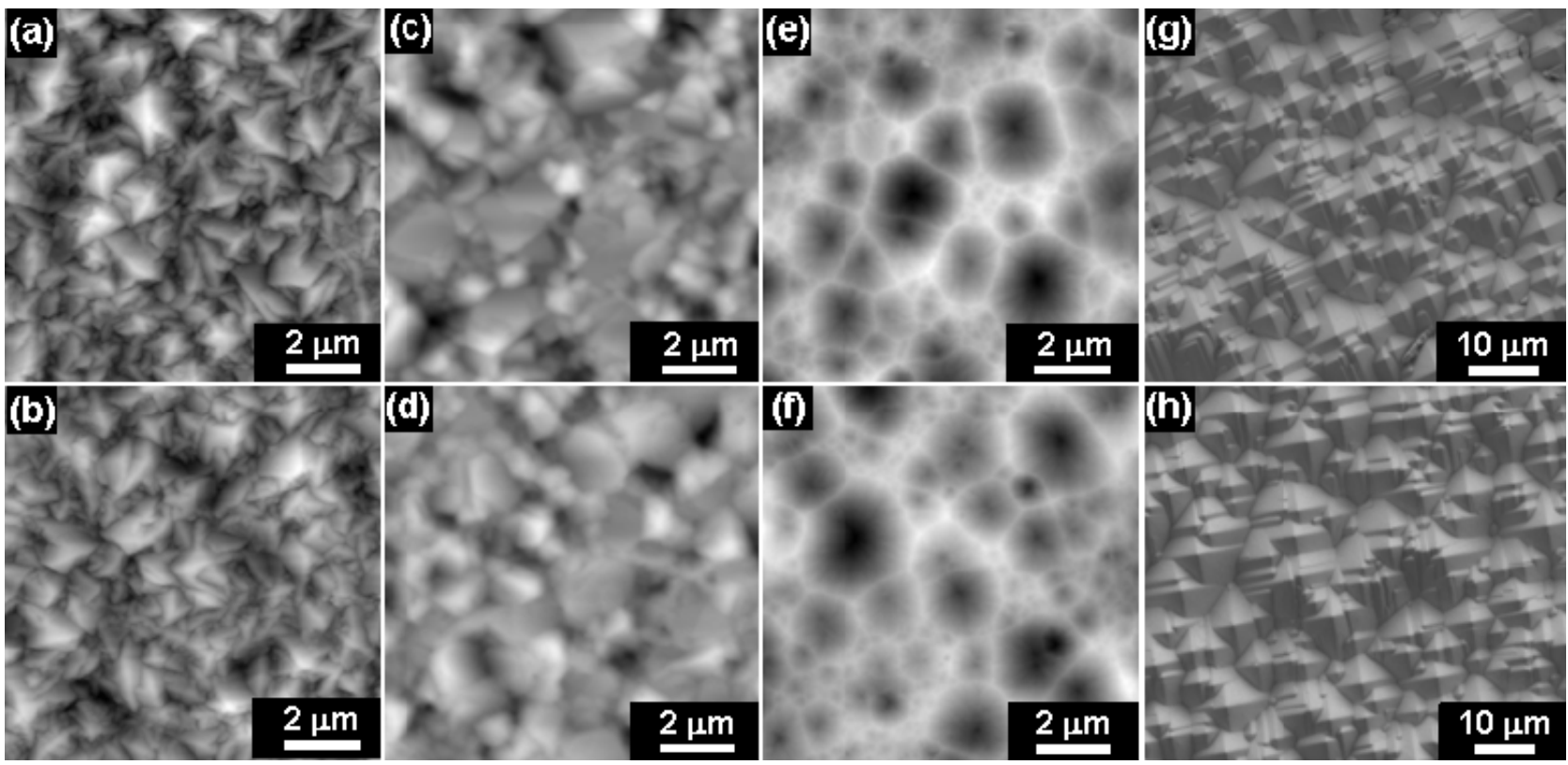

Figure 3. AFM images of (a) $5 \mu \mathrm{m}$ thick LPCVD ZnO and (b) its corresponding replica; (c) high temperature sputtered silver, and (d) its corresponding replica; (e) sputtered $\mathrm{ZnO}$ etched using $\mathrm{HCl}$ and (f) its corresponding replica; and SEM images of (g) (100) c-Si wafer textured using $\mathrm{KOH}$ and $(\mathrm{h})$ its corresponding replica.

Table 1. Summary of the parameters extracted from the AFM analysis.

\begin{tabular}{lccl}
\hline Texture & $\sigma_{\text {RMS }}(\mathrm{nm})$ & $L(\mathrm{~nm})$ & $\begin{array}{l}\text { Mean angle } \\
(\mathrm{deg})\end{array}$ \\
\hline LPCVD ZnO & & & \\
$\quad$ Master & $176 \pm 2$ & $404 \pm 6$ & $44.8 \pm 0.2$ \\
$\quad$ Replica & $174 \pm 1$ & $414 \pm 9$ & $44.5 \pm 0.7$ \\
Hot silver & & & \\
$\quad$ Master & $62 \pm 6$ & $470 \pm 19$ & $13.2 \pm 0.6$ \\
$\quad$ Replica & $58 \pm 4$ & $460 \pm 17$ & $12.7 \pm 0.6$ \\
Sputtered etched ZnO & & & \\
$\quad$ Master & $144 \pm 7$ & $797 \pm 50$ & $22.0 \pm 0.5$ \\
$\quad$ Replica & $131 \pm 11$ & $759 \pm 20$ & $19.5 \pm 1.0$ \\
\hline
\end{tabular}

Their size is thus a significant fraction of the scanned area $(10 \mu \mathrm{m} \times 10 \mu \mathrm{m})$, having a big relevance in the final statistics result. An unbalanced number of these huge craters between the AFM images of the master and the replica could explain this small deviation.

The micrometric pyramidal texture of the etched c-Si wafer and its replica were also quantitatively compared. Figure 5(c) shows the 3D surface of the replica (figure 3(h)) reconstructed from the two SEM images (figures 5(a) and (b)) measured with a different tilting $\left(0^{\circ}\right.$ and $15^{\circ}$, respectively). An equivalent image was obtained for the master. The $\sigma_{\mathrm{RMS}}$ and the correlation length values calculated for both images are given in table 2. As for previous textures, no significant differences are observed in the parameters. These results further confirm that excellent fidelity replicas of photovoltaic, multiscale random structures can be achieved by UV-NIL stamping [15].

The same process can be used to obtain the negative of any of the textures studied. This is illustrated for the LPCVD $\mathrm{ZnO}$
Table 2. Morphological parameters extracted from the three-dimensional reconstructed surface for the $\mathrm{KOH}$ etched c-Si master and replica.

\begin{tabular}{lll}
\hline & $\sigma_{\text {RMS }}(\mu \mathrm{m})$ & $L(\mu \mathrm{m})$ \\
\hline Master & 1.73 & 1.60 \\
Replica & 1.84 & 1.56 \\
\hline
\end{tabular}

in figure 6. The pyramidal pits of the negative (figure 6(b)) conform to the peaks in the master (figure 6(a)) in size and shape. The $\sigma_{\mathrm{RMS}}$ and the local mean angle $(\langle\alpha\rangle)$ calculated for the inverted texture are $45.0^{\circ}$ and $174 \mathrm{~nm}$, respectively. These values are totally comparable with the ones of the master texture (see table 1).

This high fidelity replication process provides high flexibility in designing new light trapping strategies for thin film devices. The low absorption of the UV resin allows unlinking the shape of a texture from its transparency. Thus, the texture of non-transparent master surfaces, as for example the sputtered silver or the etched c-Si wafer, can be used in $\mathrm{p}-\mathrm{i}-\mathrm{n}$. In previous work, we demonstrated the feasibility of this approach in combination with a TCO [13, 14]. Furthermore, antireflective textures for the incoming light can be implemented in the other face of the glass or on the top of the device for $n-\mathrm{i}-\mathrm{p}$ configuration. The micrometric random pyramidal texture is often used for this purpose because a double rebound of the light within its macroscopic texture diminishes the total amount of reflected light. For $n-i-p$ configuration devices, textures such as the sputtered silver or LPCVD ZnO can be stamped onto flexible plastic substrates. Direct deposition on plastic is not advised due to either the high temperature $\left(\sim 400^{\circ} \mathrm{C}\right)$ required to sputter the silver or the brittleness of the $\mathrm{ZnO}$ which easily cracks by bending the substrate. 

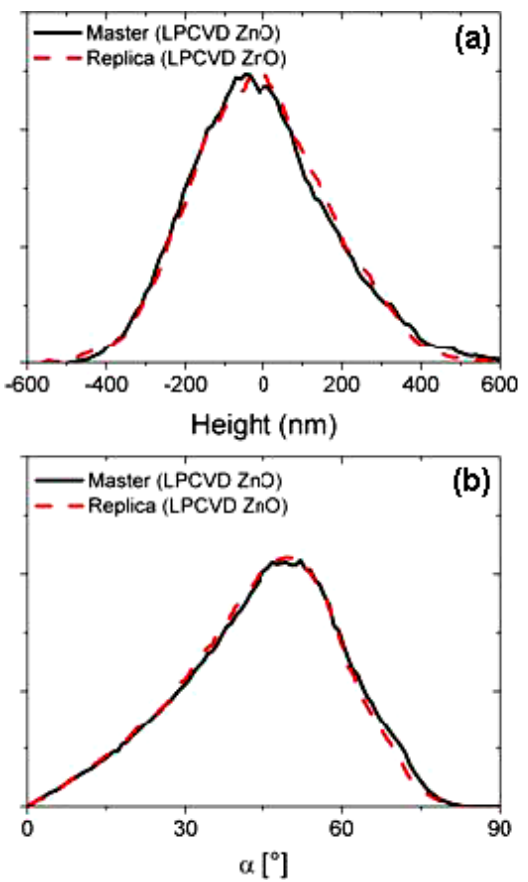
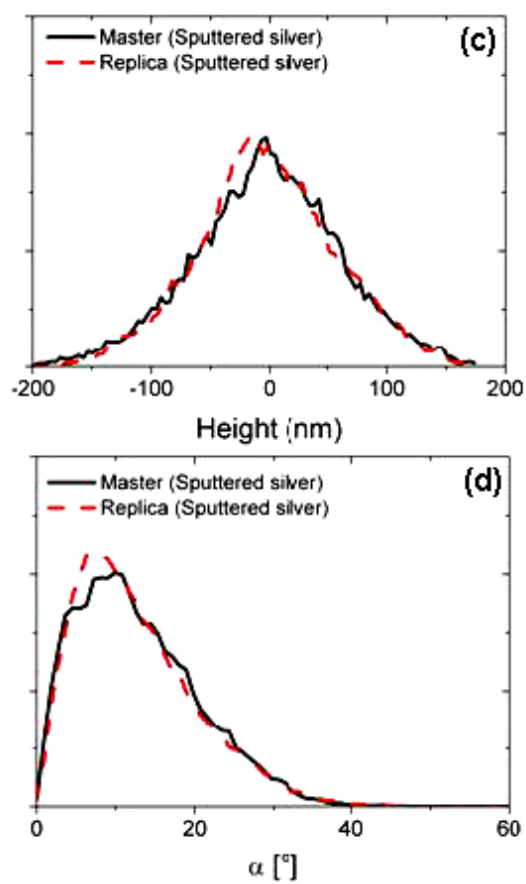
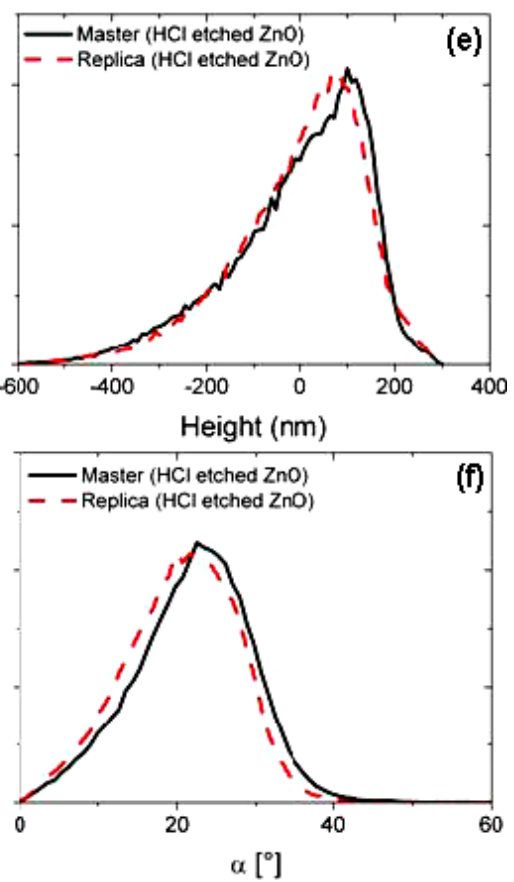

Figure 4. Height (a), (c), and (e) and local angle (b), (d), and (f) histograms measured for the masters and their corresponding replicas.
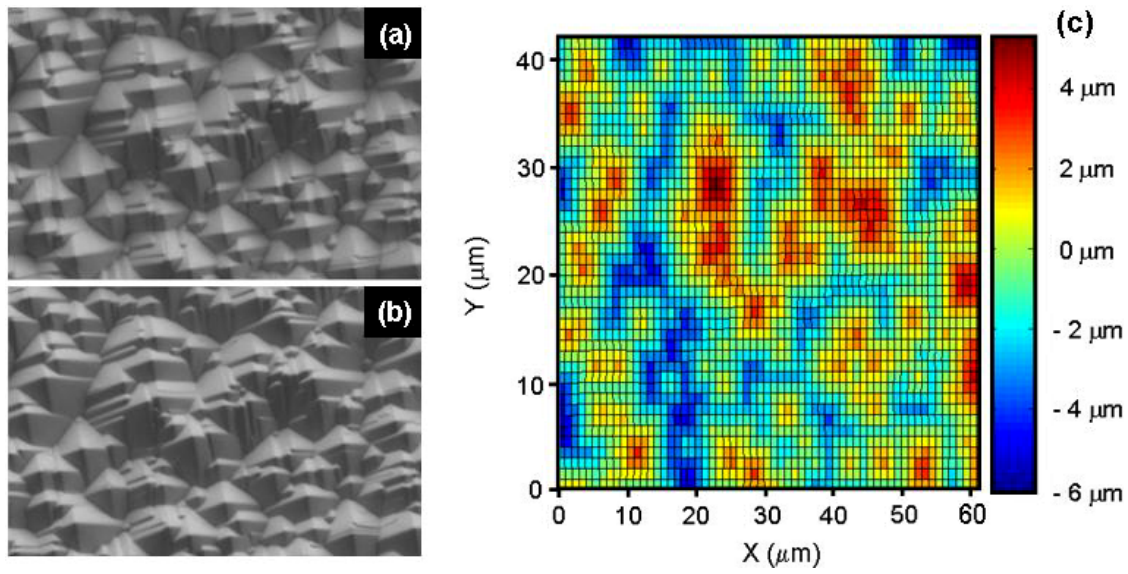

Figure 5. SEM images of the replicated $\mathrm{KOH}$ pyramids measured under an angle of (a) $0^{\circ}$ and (b) $15^{\circ}$; both images were used to approximate its three-dimensional surface (c).

Table 3. Initial parameters of the a-Si:H p-i-n cells deposited on master and replica.

\begin{tabular}{lllll}
\hline & $V_{\mathrm{oc}}(\mathrm{V})$ & $\mathrm{FF}$ & $J_{\mathrm{sc}}\left(\mathrm{mA} \mathrm{cm}^{-2}\right)$ & Efficiency $(\%)$ \\
\hline Master & 0.888 & 0.751 & 15.16 & 10.1 \\
Replica & 0.882 & 0.747 & 15.75 & 10.4 \\
\hline
\end{tabular}

\subsection{Superstrate configuration approach}

The use of UV replicas on glass as substrates for a-Si:H solar cells in superstrate configuration is discussed in this section. As in previous publications $[13,14]$, the pyramidal texture of $5 \mu \mathrm{m}$ thick LPCVD $\mathrm{ZnO}$ after $20 \mathrm{~min}$ of argon plasma treatment was used as a master to obtain high fidelity replicas. The AFM image of the surface of the master (see figure 7(a)) reveals a smoother texture compared to equivalent untreated samples (see figure 3(a)). Figure 7(b) shows the local angle histograms comparing an as-grown $\mathrm{ZnO}$ sample with the plasma treated master and replica. For the master and replica case, both curves are practically superimposed and, hence, their texture is not expected to be significantly different. The curve of the untreated sample assumes its maximum value $7^{\circ}$ shifted toward higher angles, confirming that the plasma smoothes the roughness. The smoothing has a beneficial effect on the performance of the devices (especially the $\mu \mathrm{c}-\mathrm{Si}: \mathrm{H}$ ones) by eliminating the V-shaped valleys present in the texture which are responsible for the growth of defective material [21].

Both master and replica were used as a substrate for a $\mathrm{p}-\mathrm{i}-\mathrm{n}$ co-deposited solar cell with a $250 \mathrm{~nm}$ thick intrinsic layer. The cell parameters in the initial state are summarized in table 3. As expected due to the higher sheet resistance of 

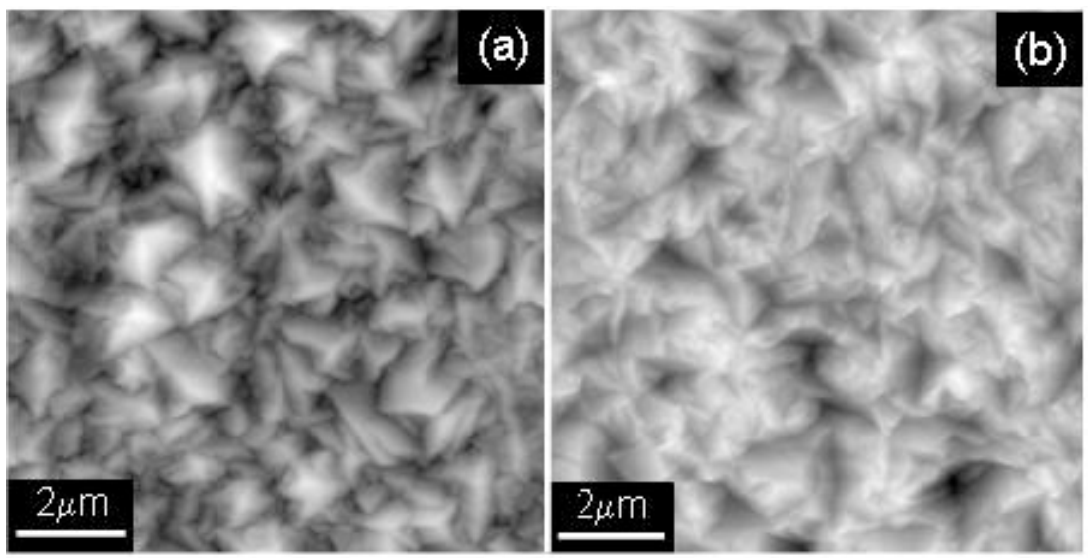

Figure 6. AFM images of (a) the LPCVD ZnO master and (b) its inverse texture obtained by UV stamping.
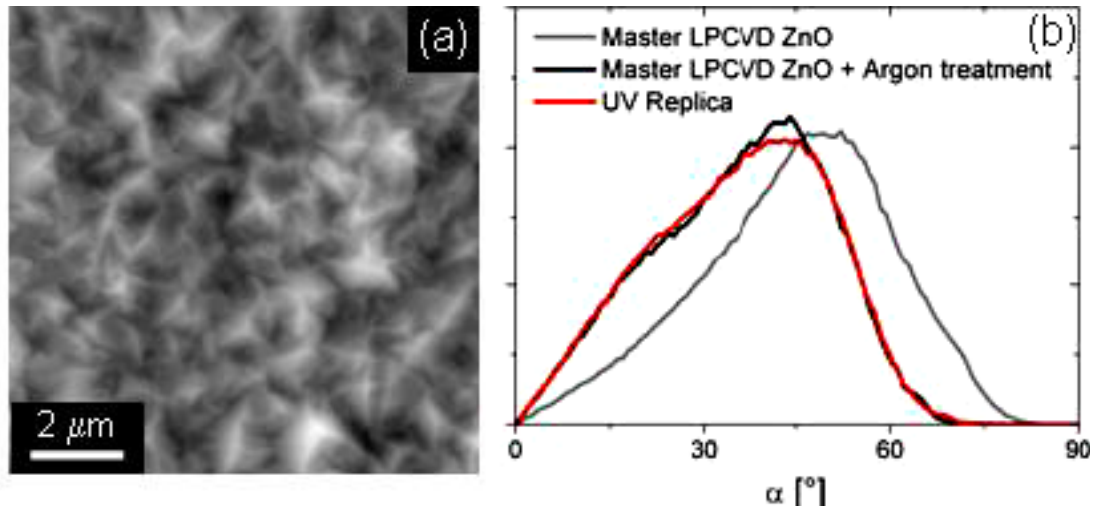

Figure 7. AFM image of $5 \mu \mathrm{m}$ thick LPCVD ZnO treated for $20 \mathrm{~min}$ with argon plasma (a); local angle histograms calculated for the treated LPCVD ZnO and its corresponding replica (b). The curve for the untreated LPCVD ZnO is added as a reference.

the ITO $(32 \Omega / \mathrm{sq})$ compared to the LPCVD ZnO $(8 \Omega / \mathrm{sq})$, slightly lower values of FF and $V_{\mathrm{oc}}$ were measured for the replica. Interestingly, the reduction in FF due to the higher sheet resistance in the replica electrode is lower than the one previously observed for $\mu \mathrm{c}$-Si:H cells [13], as a consequence of the lower current generated by the a-Si:H devices.

On the other hand, the solar cell deposited on the replica produces a higher current. The EQE curves for both cells are shown in figure 8 . The EQE for the replica is significantly higher at the short wavelength range $(350-550 \mathrm{~nm})$. However, at large wavelengths $(550-800 \mathrm{~nm})$, where the response of the cell is mainly controlled by the texture of the substrate, both curves are nearly superimposed. This suggests that the ITO electrode is more transparent than the $\mathrm{ZnO}$, but that both the surfaces have similar roughnesses, a conclusion supported by the angle histograms of the replica and master in figure 7(b) and the transmittance measurements for both TCO published in [19]. Surprisingly, the overall efficiency for the solar cell deposited on the replica $(10.4 \%)$ is higher than the one deposited on the master (10.1\%) confirming that a-Si:H p-i-n solar cells grown on UV imprinted substrates with performance comparable to the 'state of the art' devices can be obtained.

Finally, we stress that our group has already proved that UV imprinted substrates can also be successfully used in micromorph devices [14]. The same type of texture

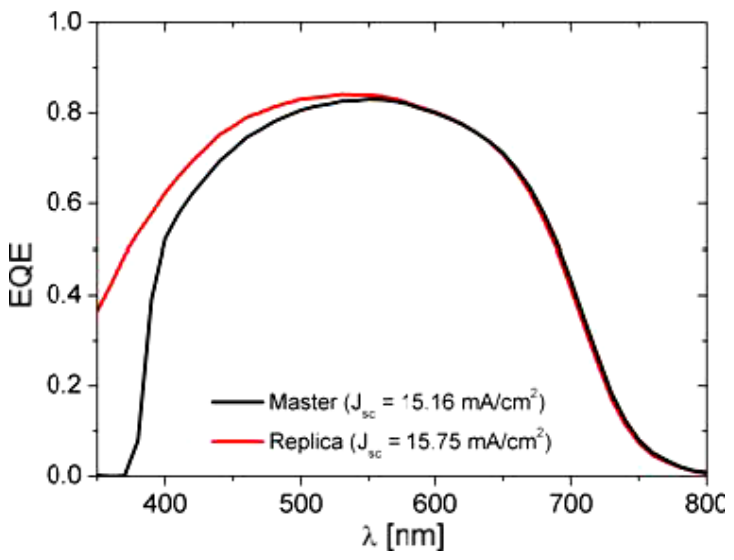

Figure 8. External quantum efficiency curves of co-deposited a-Si:H solar cells deposited on the argon plasma treated LPCVD ZnO master and replica.

(figure 7(a)) was used to compare master and replica. However, a high mobility hydrogenated indium oxide $\left(\operatorname{In}_{2} \mathrm{O}_{3}: \mathrm{H}\right)$ layer was sputtered as a front electrode to further reduce free carrier absorption at large wavelengths. This front electrode presents a lower optical absorption but a higher electrical resistance compared to the LPCVD zinc oxide master [19]. 

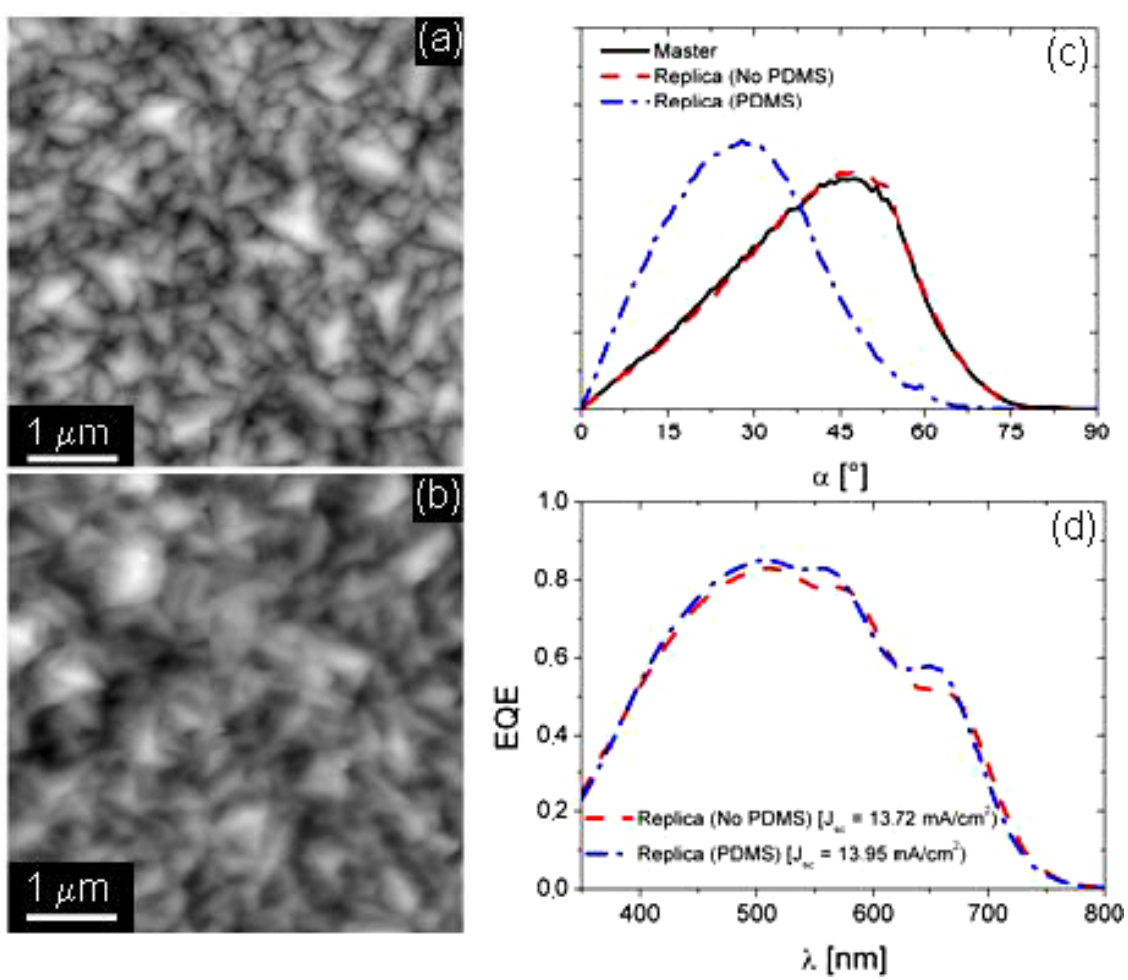

Figure 9. AFM images of (a) a high fidelity and (b) a PDMS smoothed replica imprinted using a $2 \mu \mathrm{m}$ thick LPCVD ZnO master, with the calculated local angle histograms (c) to compare both textures with the original one. The external quantum efficiency curves of co-deposited a-Si:H solar cells grown on both types of replica are shown in (d).

Table 4. Initial parameters of the micromorph cells deposited on the master and replica [11].

\begin{tabular}{llllll}
\hline & $V_{\text {oc }}(\mathrm{V})$ & FF & $\begin{array}{l}J_{\text {sc }}(\text { top }) \\
\left(\mathrm{mA} \mathrm{cm}^{-2}\right)\end{array}$ & $\begin{array}{l}J_{\text {sc }}(\text { bottom) } \\
\left(\mathrm{mA} \mathrm{cm}^{-2}\right)\end{array}$ & $\begin{array}{l}\text { Efficiency } \\
(\%)\end{array}$ \\
\hline Master & 1.385 & 72.6 & 11.9 & 12.1 & 12.0 \\
$\begin{array}{l}\text { Replica }+ \\
\mathrm{In}_{2} \mathrm{O}_{3}: \mathrm{H}\end{array}$ & 1.359 & 68.7 & 12.9 & 13.0 & 12.0 \\
\hline
\end{tabular}

Table 4 summarizes the cell parameters measured for both master and replica. The higher current on the replica compensates its lower values of $\mathrm{FF}$ and $V_{\mathrm{oc}}$, leading to exactly the same $12 \%$ efficiency as the master. Thus, the combination of UV imprinted substrates plus ITO or hydrogenated indium oxide allows an acceptable decoupling of the front contact morphology from its electrical properties in both amorphous and micromorph devices. The constraints regarding cost, transparency, and electrical conductivity in testing new light trapping textures in the front electrode have become significantly less important by using this UV microtexturing approach, an important tool that can help to further increase the efficiency of the micromorph solar cells.

\subsection{Substrate configuration approach}

In this section, we present results concerning nanostructuration of flexible PEN to be used as a substrate for a-Si:H silicon solar cells in $\mathrm{n}-\mathrm{i}-\mathrm{p}$ configuration. LPCVD $\mathrm{ZnO}(2 \mu \mathrm{m}$ thick) was used as a master texture in the replication experiments. First
Table 5. Initial parameters of the cells deposited on both type of replicas.

\begin{tabular}{lllll}
\hline & $V_{\mathrm{oc}}(\mathrm{V})$ & $\mathrm{FF}$ & $\begin{array}{l}J_{\mathrm{sc}} \\
\left(\mathrm{mA} \mathrm{cm}^{-2}\right)\end{array}$ & $\begin{array}{l}\text { Efficiency } \\
(\%)\end{array}$ \\
\hline High fidelity & 0.834 & 0.68 & 13.72 & 7.8 \\
Replica PDMS & 0.865 & 0.70 & 13.95 & 8.4 \\
\hline
\end{tabular}

tests were carried out on glass. Two different intermediate molds were fabricated to provide high fidelity (figure 9(a)) and smoothed textures (figure $9(\mathrm{~b})$ ) from the original. The first mold was obtained by the method described in the experimental part, while for the second, soft lithography using polydimethylsiloxane (PDMS) was used [12]. The local angle histogram for the PDMS replica was significantly shifted toward lower angles, indicating a loss in the steepness of its surface features (figure 9(c)). The smoothing observed using PDMS has already been reported previously [15].

Both replicas were used as a substrate for co-deposited single junction $n-i-p$ solar cells with a $200 \mathrm{~nm}$ thick intrinsic layer (nominal value). Table 5 summarizes cell parameters in the initial state for both replicas. Unexpectedly, the cell deposited on the smoother replica was found to have the highest current (figure 9(d)). The opposite trend was previously observed for $\mathrm{p}-\mathrm{i}-\mathrm{n}$ devices deposited on similar samples, achieving less current for the one grown on the smoother texture [15]. The absorption of the device, on the other hand, is higher for the rougher replica (not shown), pointing to some extra parasitic absorption on the silver 


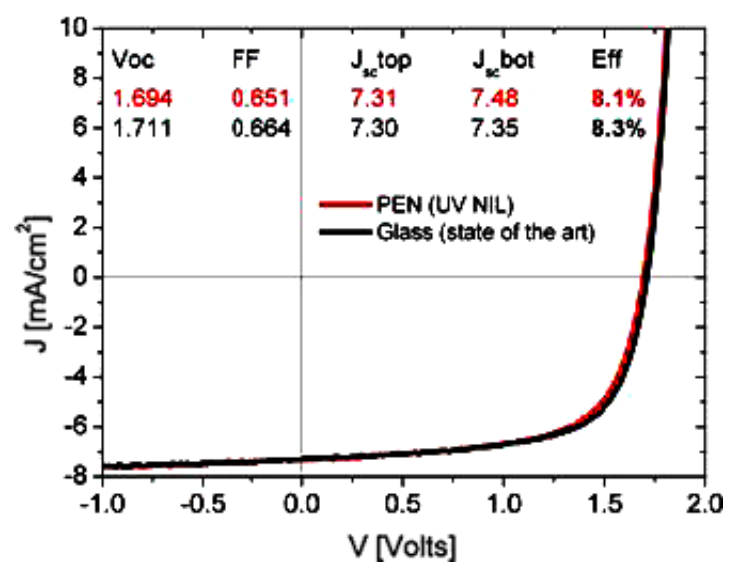

Figure 10. $J-V$ curves in the stabilized state of two a-Si/a-Si tandem cells deposited on UV stamped PEN and on glass as a reference. The main cell parameters are also summarized for both cells.

back reflector [22]. Obtaining less absorbing silver reflectors becomes easier on smoother substrates than on highly textured ones. Moreover, as expected for its smoother texture, the PDMS replica also leads to better $V_{\mathrm{oc}}$ and FF values for the device (see table 5). For this particular master and device configuration, the smoothing of the original texture appears to be beneficial for the device performance, obtaining an overall efficiency of $8.4 \%$, significantly higher than the $7.8 \%$ obtained for the high fidelity replica.

In view of the results, the same PDMS mold was selected to transfer its texture on PEN. An a-Si:H/a-Si:H tandem solar cell was deposited with top and bottom cell thicknesses of 60 and $300 \mathrm{~nm}$, respectively. The cell was stabilized after $1000 \mathrm{~h}$ of light soaking at $65^{\circ} \mathrm{C}$ and light intensity of $100 \mathrm{~mW} \mathrm{~cm}^{-2}$. Its $J-V$ curve and cell parameters are summarized and compared with a 'state of the art' device obtained on glass which is used as a [23] (see figure 10). Although, the texture of the substrates is different, a stable efficiency close to the reference one was achieved on UV stamped PEN.

\section{Conclusions}

UV imprinting has been proven as a suitable technique to replicate textures, commonly used in photovoltaics, with an excellent fidelity. We showed that this technique is able to replicate random textures, either on glass or PEN, with different dimensions (nanometric or micrometric sizes) and shapes. Moreover, UV imprinting can be used to invert original textures with an equivalent fidelity.

The development of both $\mathrm{p}-\mathrm{i}-\mathrm{n}$ and $\mathrm{n}-\mathrm{i}-\mathrm{p}$ solar cells incorporating these replicated textures has resulted in device efficiencies fully comparable to the ones obtained for the original structures. These results have shown UV imprinting as feasible to reproduce future optimized light trapping textures from costly to cheap substrates for thin film solar cell applications.

\section{Acknowledgments}

The authors gratefully acknowledge support by the Swiss Federal Office for Energy (OFEN) under contract 101191, the Swiss Commission for Technology and Innovation (CTI) within project no. 8809.2, and the Swiss National Science Foundation under grant 200021-125177.

\section{References}

[1] Faÿ S, Steinhauser J, Nicolay S and Ballif C 2010 Thin Solid Films $\mathbf{5 1 8} 2961-6$

[2] Kluth O, Rech B, Houben L, Wieder S, Schöpe G, Beneking C, Wagner H, Löffl A and Schock H W 1999 Thin Solid Films $351247-53$

[3] Guha S and Yang J 2006 J. Non-Cryst. Solids 352 1917-21

[4] Zhu J, Hsu C-M, Yu Z, Fan S and Cui Y 2010 Nano Lett. 10 1979-84

[5] Cai W and Shalaev V 2010 Optical Metamaterials (New York: Springer Science + Business Media)

[6] Saison T, Peroz C, Chauveau V, Berthier S, Sondergard E and Arribart H 2008 Bioinsp. Biomim. 3046004

[7] Escarré J, Villar F, Fonrodona M, Soler D, Asensi J M, Bertomeu J and Andreu J 2005 Sol. Energy Mater. Sol. Cells $87333-41$

[8] Heijna M C R, Löffler J, Van Aken B B, Soppe W J, Van Erven R, Franken R, Borg H and Peeters P P G J M 2008 Proc. SPIE 7047704706

[9] Ding I-K et al 2011 Adv. Energy Mater. 1 52-7

[10] Ahn S H, Kim J S and Guo L J 2007 J. Vac. Sci. Technol. B 25/26 2388-91

[11] Bailat J et al 2005 Proc. 20th EU Photovoltaic Solar Energy Conf. pp 1529-32

[12] Söderström K, Escarré J, Cubero O, Haug F J, Perregaux S and Ballif C 2011 Prog. Photovolt.: Res. Appl. 19 202-10

[13] Battaglia C et al 2010 Appl. Phys. Lett. 96213504

[14] Battaglia C et al 2011 Nano Lett. 11 661-5

[15] Escarré J, Söderström K, Battaglia C, Haug F J and Ballif C 2011 Sol. Energy Mater. Sol. Cells 95 881-6

[16] Niggemann M, Riede M, Gombert A and Leo K 2008 Phys. Status Solidi a 12 2862-74

[17] Kuchler G and Brendel R 2003 Prog. Photovolt.: Res. Appl. 11 89-95

[18] Hylton J D 2006 PhD Thesis University of Utrech, The Netherlands

[19] Battaglia C et al 2011 J. Appl. Phys. 109114501

[20] Minami T, Sato H, Nanto H and Takata S 1989 Thin Solid Films 176 277-82

[21] Python M, Dominé D, Söderström T, Meillaud F and Ballif C 2010 Prog. Photovolt.: Res. Appl. 18 491-9

[22] Söderström K, Haug F J, Escarré J, Pahud C, Biron R and Ballif C 2011 Sol. Energy Mater. Sol. Cells 95 3585-91

[23] Cubero O, Haug F J, Ziegler Y, Sansonnens L, Couty P, Fischer D and Ballif C 2011 Sol. Energy Mater. Sol. Cells 95 606-10 